
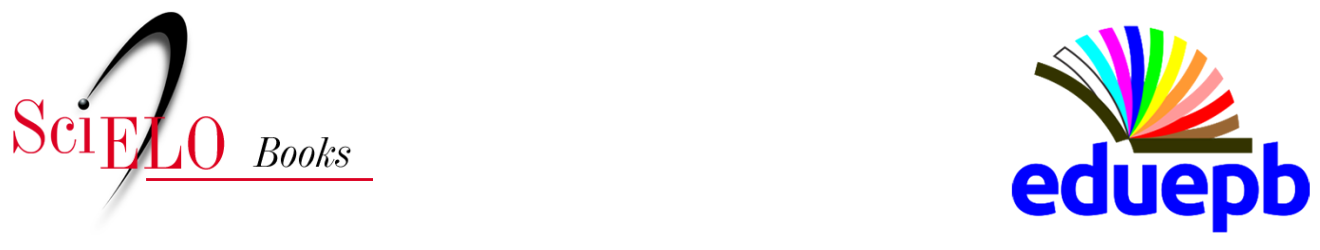

Parte II - Políticas, Escalas, Territórios

\title{
Política Nacional de Desenvolvimento Regional no Brasil - Incapacidade ou Não-Acontecimento? Uma Interrogação Pendente
}

\author{
Rainer Randolph
}

\section{SciELO Books / SciELO Livros / SciELO Libros}

RANDOLPH, R. Política Nacional de Desenvolvimento Regional no Brasil Incapacidade ou Não-Acontecimento? Uma Interrogação Pendente. In: SOUSA, C. M., THEIS, I. M., and BARBOSA, J. L. A., eds. Celso Furtado: a esperança militante (Desafios): vol. 3 [online]. Campina Grande: EDUEPB, 2020, pp. 165-192. Projeto editorial 100 anos de Celso Furtado collection, vol. 3. ISBN: 978-65-86221-12-1. https://doi.org/10.7476/9786586221688.0007.

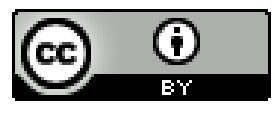

All the contents of this work, except where otherwise noted, is licensed under a Creative Commons Attribution 4.0 International license.

Todo o conteúdo deste trabalho, exceto quando houver ressalva, é publicado sob a licença Creative Commons Atribição 4.0.

Todo el contenido de esta obra, excepto donde se indique lo contrario, está bajo licencia de la licencia Creative Commons Reconocimento 4.0. 


\section{Política Nacional de \\ Desenvolvimento Regional no Brasil - Incapacidade ou Não-Acontecimento? \\ Uma Interrogação Pendente}

Rainer Randolph ${ }^{1}$

\section{Introdução}

"Captar a natureza do subdesenvolvimento não é tarefa fácil; muitas são as dimensões e as que são facilmente visíveis nem sempre são as mais significativas" (FURTADO 1974, p. 22). Apesar do presente trabalho não estar voltado às mencionadas dimensões, essa expressão pode ser seu lema; ou seja, ao invés de ter como objeto o subdesenvolvimento, procura-se identificar a "natureza" daqueles que estão "envolvidos" no "des"-envolvimento. Aí vale a frase quase ipsis litteris: identificar a natureza daqueles que são responsáveis pelo desenvolvimento (e, por tabela, o não-desenvolvimento) não é tarefa fácil porque muitas das dimensões facilmente visíveis nem sempre - ou, talvez, raras vezes - são as mais significativas.

Talvez não seja tão difícil encontrar as muitas "dimensões" que permitiriam identificar a natureza daqueles que contribuem para o desenvolvimento. Na literatura encontram-se indicações de diferentes dimensões a partir de diversas abordagens (démarches) que não serão citadas aqui. O próprio Furtado é considerado um dos mais importantes autores, não apenas por sua produção intelectual, mas também como "envolvido" por causa da sua atuação como planejador em vários órgãos governamentais durante muitos anos.

1 Professor Titular aposentado da UFRJ; Prof. Colaborador Voluntário e docente permanente do Programa de Pós-Graduação em Planejamento Urbano e Regional do Instituto de Pesquisa e Planejamento Urbano e Regional (IPPUR/UFRJ, e-mail: rainer. randolph@gmail.com. 
No âmbito do espaço limitado de presente capítulo, deve-se ter, primeiro, uma resposta ao desafio de Furtado de não eliminar, de antemão, dimensões significativas da exposição. Eis uma questão "dialética", à medida que o julgamento sobre importância ou significado de uma dimensão exigiria o conhecimento da totalidade das dimensões da qual as mais significativas constituem um grupo particular. Este o dilema metodológico de qualquer processo de produção de conhecimento, que tem a pretensão de revelar algo que não seja apenas a "aparência" relativamente pouco significativa de um fenômeno

De alguma forma como expressão dessa dialética - post factum -, adota-se os seguintes procedimentos e providências:

1. inicialmente, no primeiro item, será indicada a política de desenvolvimento regional em nível federal como assunto da investigação, delimitando seu horizonte histórico e os recortes regionais contemplados. Assim, o estudo se refere a manifestações políticas pelo Estado brasileiro e diferentes governos mais ou menos facilmente visíveis de (des) envolvimento dos anos 1950/6o até o presente. Especificamente, interessam características de políticas de desenvolvimento regional formuladas e/ ou implementadas pelos diferentes governos federais dos anos de 1950 a 1963 e do período de 2003 a 2019, como referencia empírica do presente trabalho. Numa breve apreciação da literatura sobre estes assuntos será identificada a dimensão dos resultados obtidos por essas políticas como a mais significativa para sua apreciação. À medida que esta parte visa apontar a referência empírica do estudo e contribuir para uma primeira problematização, a análise das referidas políticas não será aprofundada;

2. a finalidade da parte seguinte será mostrar as limitações de julgar sucesso ou fracasso dessas políticas de desenvolvimento regional apenas a partir de seus (aparentes) resultados. É necessário, para identificar possíveis dimensões mais "ocultas", contemplar, também, além da execução de políticas - alcance ou não de metas, objetivos etc, - as formas de sua articulação/ formulação e instituição/ institucionalização. Assim, como forma de afastar-se de um víeis positivista, "resultados" precisam ser compreendidos, também, como uma forma de exclusão de outras possibilidades. Aquilo que chamamos de "não-acontecimentos" são tão "resultados" como os próprios; sua "produção" antecede, em muitos casos, a própria instalação da política ou mesmo ocorre concomitantemente a caminho do alcance de determinados resultados. São expressão de "potencialidades" de uma política não realizadas por determinadas 
"razões" que, muitas vezes, são apenas mencionadas genericamente sem maior investigação enquanto forças que impedem "outros resultados". Será mostrado que a identificação e qualificação dessa dimensão como "significativa" é possível e necessária. Assim, aqui será introduzida uma dimensão institucional e estrutural da produção desses "resultados" - do "não-acontecido" - onde se dará ênfase à produção dessa sua "natureza", variável com o tempo;

3. no próximo item, essa discussão será continuada por meio da apresentação de uma outra dimensão ligada a processo de ação e atuação governamental, que dirige a atenção à "dialética" entre estrutura institucional e dinâmicas de atuação, numa perspectiva da execução de políticas. Articulação dialética, diga-se de passagem, que não se revela sob a observação de falta de sucesso ou de possíveis fracassos das políticas; precisam ser contemplados os processos de atuação dos governos.

4. finalmente, a breve conclusão retoma a pergunta do título do presente trabalho a respeito da caracterização das políticas de desenvolvimento regional que serviam aqui como ilustração. Não há como adiantar respostas definitivas se suas "falhas" tem sua origem em certas incompetências; ou que apontam para sua compreensão como "não-acontecimento" na medida que uma boa parte das apreciações por especialistas e estudiosos questiona até se devam ser consideradas como de desenvolvimento regional. De alguma forma, até Celso Furtado (2002, p.36) vai propor, numa publicação de 2002 , que um processo de reconstrução de políticas regionais deve considerar uma maior participação popular no sistema das decisões. As dificuldades de seguir neste caminho são brevemente apontadas no final da argumentação do presente texto.

\section{Políticas de desenvolvimento regional desde a década de 1950}

Na literatura há certa diversidade e discordância entre as abordagens sobre as principais características de diferentes períodos históricos na trajetória de políticas brasileiras de desenvolvimento regional. Além de diferentes caracterizações, há divergências mesmo em relação à abrangência histórica e territorial das suas periodizações. Apenas para ilustrar, Pitanga (2014) aponta cinco etapas históricas da política regional 
brasileira de 1877 a $2002^{2}$; uma sexta de 2003 adiante não é mencionada. Já Carvalho (2014, p. 298-305) observa, ao abordar a experiência passada do desenvolvimento regional no Brasil, que "planejamento e desenvolvimento regional no Brasil nasceu no Nordeste" cuja experiência abrange os 30 anos que vão de 1950 ao final dos anos 1980. Gumiero (2017), também em relação à política regional para o Nordeste, diferencia quatro fases desde a década de 1950 até ao governo Lula e Dilma Rousseff, de 2003 a 2014. As periodizações estão vinculadas, também, a cada vez mais específicas regionalizações das políticas de desenvolvimento.

Dentro do foco do atual trabalho, não é preciso entrar numa discussão a este respeito. Pode-se constatar um certo consenso dos analistas - e senso comum na sociedade - que as desigualdades econômicos e sociais entre estados e suas aglomerações em (macro) regiões constituem o principal problema e dão origem a propostas e intervenções regionais do governo federal. Como é sabido, a região Nordeste se destaca como principal alvo destes esforços durante um longo período da história brasileira.

Esse enfoque da política da União pode se verificar - diferenciadamente - em dois momentos históricos, que servem para a atual discussão como referencial e ilustração desses períodos. Não será necessário aprofundar alcance ou não das proposições e objetivos de suas políticas à medida que se pretende apenas apresentar apreciações de autores a respeito de seus supostos "sucessos" ou "fracassos". São contextos importantes para o presente estudo, porque essas "realidades" vão justificar a perspectiva aqui adotada

Começando pelo momento mais recente, este se inicia em 2003 quando o recém-empossado presidente Luiz Inácio Lula da Silva começa a cumprir um compromisso assumido durante a campanha eleitoral, e atribui prioridade ao problema das desigualdades regionais na sua agenda política, com a formulação de uma Política Nacional de Desenvolvimento Regional (PNDR). Resultado de uma série de esforços prévios de analises e diagnósticos 3 , só em 2007 no início da segunda gestão do governo Lula será institucionalizada por Decreto Presidencial № 6.047, de 22 de fevereiro daquele ano. A emergência dessa política foi, conforme Macedo e

2 O autor indica que essa periodização da intervenção do governo na questão regional é uma adaptação do documento de referência da Conferência Nacional de Desenvolvimento Regional (BRASIL 2012) e do relatório "Fundos Constitucionais de Financiamento", ambos disponíveis no site do MI.

3 Vide a sistematização em Costa (2016) e sua indicação de um trabalho de Araújo de 1999, considerado da maior influência para a formulação da política; 
Porto (2018, p. 611), "considerada um marco na retomada da questão do desenvolvimento regional, após mais de duas décadas de esvaziamento das políticas anteriores e dos instrumentos para combater as iniquidades regionais no país" 4 .

Em termos de seus resultados essa PNDR não foi considerada uma história de sucessos porque, naquele momento, sua proposta, apesar de levantar "pontos da maior importância para a questão regional brasileira ... não chegou a ser concretizada em termos institucionais e no tocante aos meios e instrumentos necessários para sua implantação" (GUIMARÃES NETO 2012, p. 206). Alegou-se que possíveis avanços de redução de desigualdades regionais durante os anos do então governo devam ser creditados a resultados regionalmente diferenciados de políticas setoriais. $\mathrm{Ou}$ seja, a redução (relativa) de tais desigualdades (BRANDÃO 2014, p. 340) se deveu às características das políticas setoriais implementadas, e não a uma atuação regional deliberada5.

A respeito de um renovado esforço, a partir de 2012, de criar uma nova Política Nacional de Desenvolvimento Regional (PNDR II) enquanto lei, Brandão (2014, p. 339) já chamou atenção, em 2014, para o perigo de a nova PNDR II ter o mesmo destino da versão anterior, apesar de ter considerado seu resultado bastante coerente. Nem tanto pelas razões alinhadas por Guimarães Neto, mas por causa da escassez "de atores políticos de peso que sustentam uma política de tal complexidade" (BRANDÃO, 2014, p. 342). E mesmo a formulação de uma proposta da PNDR II por meio de um amplo processo de consulta e participação não consolidou, como segue o autor, "a legitimação e força política suficientes para romper o impasse da implementação de políticas nacionais e regionais de desenvolvimento .... Ou seja, atribuiu a responsabilidade pela, então, possível não aprovação do projeto de lei da PNDR II e de sua subsequente não implantação, a determinadas circunstâncias (forças) políticas e sociais. E além de poder faltar sustentação, Brandão (2014, p. 342) vê, mais

4 Vide também Silva (2016, p. 373) que considerou que a principal novidade expressa pela PNDR, além de trazer de volta a temática do desenvolvimento regional à agenda pública, foi o fato de ser a primeira experiência verdadeiramente nacional de desenvolvimento regional, isto é, com foco de atuação diferenciada de acordo com as realidades inter-regionais e intrarregionais em todo o território brasileiro."

5 Conforme relata Coelho (2015, p. 280) Guimarães Neto diferencia políticas e ações explicitamente voltadas para o desenvolvimento regional e políticas e ações implicitamente regionais; vide também a definição em Silva (2015, p.22) que "políticas regionais implícitas" são aquelas políticas setoriais com abordagem territorial; para isto também Brandão (2019) 
radicalmente, a possibilidade de ser ativamente combatido e interditado por "forças arcaicas e conservadoras" da sociedade brasileira.

Os receios de Brandão vão se tornar realidade em 2019. Em 30 de maio daquele ano, sem ter sido anunciado no programa do candidato vitorioso à presidência nas eleições de $2018^{6}$, o Governo recém-empossado em janeiro institui pelo Decreto № 9.810 da Presidência da República uma nova Política Nacional de Desenvolvimento Regional (PNDR). Revoga o supramencionado decreto de 2017 a respeito do mesmo assunto e determina como sua finalidade "reduzir as desigualdades econômicas e sociais, intra e inter-regionais, por meio da criação de oportunidades de desenvolvimento que resultem em crescimento econômico, geração de renda e melhoria da qualidade de vida da população" (BRASIL 2019).

Desta forma, a não institucionalização da PNDR II desde 20137, confirmam as conjecturas de Brandão a respeito de seu "destino", pois ela foi implicitamente "enterrada" pelo decreto de 2019, que revogou a política anterior (PNDR I), em vigor até aquele momento, e ignorou a tramitação do respectivo projeto de lei da PNDR II no Congresso. Diante das mudanças no quadro político-governamental do país ocorridas após o fim do primeiro mandato da Presidente Dilma, já manifestamos (RANDOLPH 2017) nosso ceticismo em relação à aprovação e implantação do projeto de Política Nacional de Planejamento Regional de 2012/2013, ou mesmo de iniciativas semelhantes em nível federal.

Em 2007 deu-se a institucionalização da PNDR. Neste mesmo ano foram refundadas, por Lei Complementar, duas superintendências de desenvolvimento: a do Nordeste (Sudene) - a primeira experiência de política regional formulada e implementada no Brasil - e a da Amazônia (SUDAM), a primeira tendo sido criada em 1959, a segunda em 1967. Ambas haviam sido extintas em 2001.

A divergência que surgiu por ocasião da recriação dessas duas superintendências parece confirmar a impressão de que a dimensão mais significativa neste debate foi algum tipo de resultado que se esperava em vista das metas dessas políticas. Com o argumento de precisar conter as desigualdades dessas duas regiões em relação às demais, alguns autores ${ }^{8}$ apoiaram essa medida, quando outros argumentaram contra ao considerar a recriação desnecessária, uma vez que mesmo durante a fase do início

6 Vide RANDOLPH 2018.

7 A proposta visava que a PNDR não seria apenas aprovada como uma política de governo, mas se tornaria uma política de Estado.

8 Vide as indicações em Horsth et ali (2017, p. 549). 
de seu funcionamento até sua extinção não tinham conseguido modificar, substancialmente, a estrutura de desenvolvimento regional brasileiro" Uma posição mais ponderada defendeu Costa (2016, p.9), à medida que chama a atenção que, ao julgar as realizações do planejamento regional efetuadas pela Sudene, se considere as condições nas quais foram "constritas nas possibilidades históricas concretas, que constroem caminhos mais ou menos obstaculizados para que o Estado exerça sua 'autonomia relativa'",

Caracterização e apreciação da elaboração e realização de medidas de desenvolvimento regional para a região Nordeste do país, nos anos 1950 e início de 1960 por parte da Sudene, já foram amplamente discutidas nos meios acadêmicos e político-social. Atribui-se ao economista Celso Furtado um protagonismo (CABRAL, 2011) em sua participação na formulação da Política Nacional de Desenvolvimento Regional do Nordeste no âmbito do Grupo de Trabalho para o Desenvolvimento do Nordeste $(\text { GTDN })^{10}$ e na criação da Sudene.

Contra a oposição das oligarquias nordestinas" ${ }^{11}$, com o apoio dos deputados do Centro Sul ao relatório do GTDN a Sudene foi criada

em dezembro de 1959, pela lei no 3.692 , com a finalidade de executar a política de desenvolvimento proposta para a região nordestina. Junto à lei que criou esse órgão, instituirram-se, inicialmente, dois mecanismos de incentivo (artigos 18 e 19, respectivamente) no sentido de atrair investimentos para o Nordeste (ALMEIDA, ARAÚJO 2004, p. 104).

Conforme Costa (2016, p. 69) foi objetivo da Sudene não apenas a modernização econômica, mas também a "modernização política" da região. Foi convicção de Celso Furtado que o fortalecimento da burguesia

9 Como observam Pessoa e Milani (2013), mesmo em 2017, que os problemas regionais relacionados ao crescimento econômico, emprego e renda, pobreza extrema e saúde ainda estão presentes.

10 O GTDN, criado pelo presidente Juscelino Kubitschek em 1958 (GTDN 1967).

11 Um dos principais argumentos contra a aprovação da Sudene era o temor de que haveria um controle excessivo do Governo Federal na região e a priorização da industrialização em detrimento de problemas regionais - como por exemplo, a seca. "Mas, por trás das críticas, estava o receio de que a criação do novo órgão interferisse significativamente no padrão usual de direcionamento e apropriação de recursos federais pela oligarquia agrária nordestina, com o agravante de que o novo órgão também teria o importante papel de fiscalizar o uso das mesmas" (COSTA, 2015, p. 70). 
industrial do Nordeste seria capaz de enfrentar a tradicional elite agrária (COSTA 2016, 73).

O originalmente planejado sistema de captação de recursos para o empresariado regional ("sistema 34/12) acabou sendo desvirtuado ao permitir que empresários de outras regiões (Centro-Sul) abrissem filial na área da Sudene, o que incentivou a transferência de frações do capital industrial dessas regiões (e seus interesses) para o Nordeste. Mas, como afirma Costa (2016, p. 73), "não foi apenas no sistema de captação de recursos que a instituição teve que se reajustar ou viu parte de seu planejamento inicial frustrado".

Diferente da formulação das propostas de diferenciação regional das PNDR I e II no século XXI, a Sudene, por meio da aparência de neutralidade do planejamento, surge

\begin{abstract}
como desfecho de um processo agudo de transformações e conflitos sociais, políticos e econômicos, com suas respectivas implicações, tornando o Estado produtor também no Nordeste, à exemplo do que já ocorria no Sudeste. No plano do discurso, a problemática era traduzida como "questão regional", "região problema", "conflitos interregionais" e "ameaça à unidade nacional".. (COSTA 2016, p. 86)
\end{abstract}

De outro lado, no plano político-prático, a questão a ser resolvida pela atuação regional do governo federal foi a integração nacional num momento mais intenso do debate, à segurança nacional. Essas observações levam a duvidar da "natureza" das políticas de desenvolvimento para o Nordeste - ou seja, questionar, pelos seus resultados, sua falta de sucesso ou mesmo fracasso.

Não se trata de evitar apreciar as diversas iniciativas de política nacional de desenvolvimento regional entre os anos 1950 e as duas primeiras décadas do século XXI. Compreende-se aqui que a política de desenvolvimento da Sudene e as formulações da PNDR constituem dois momentos significativos numa sequência de esforços cujos resultados podem ser questionados, embora se reconheçam certos méritos e conquistas logradas.

Seria até mesmo possível duvidar se houve em algum momento da história brasileira realmente, em nível federal, uma sistemática e coerente atuação governamental para elaborar e implementar políticas que pudessem ou mesmo quisessem contribuir para soluções dos problemas de desigualdades regionais no país. Apesar de ter apresentado poucas 
indicações a respeito das políticas aqui mencionadas, é possível concordar com a afirmação de Brandão (2010, p. 102)

.. o Brasil nunca conheceu verdadeiro processo de desenvolvimento, posto que, malgrado dispor de mecanismos dinâmicos de crescimento econômico cíclico, convive com poderosas e permanentes estruturas de reprodução de desigualdades que ampliam suas heterogeneidades estruturais e perenizam sua situação de subdesenvolvimento.

Ou seja, a dimensão na qual as políticas são julgadas diz respeito a sua incapacidade de romper "com poderosas e permanentes estruturas de reprodução de desigualdades”, enquanto um resultado necessário para permitir um verdadeiro processo de desenvolvimento. Como já mencionado antes, implicitamente, possíveis políticas de desenvolvimento regional são desta forma consideradas ou como fracassadas, valendo para aquelas antes mencionadas; ou como até inexistentes, o que se aplicaria ao período das últimas décadas do século XX.

Uma dimensão significativa para compreender uma política certamente são os resultados visíveis e sua relação, ou mesmo o confronto, com as intenções (discurso de metas, objetivos, projeto etc.) previamente declaradas e seu potencial instrumental ${ }^{12}$. Mas, ao priorizar essa dimensão corre-se o risco de se deixar de perceber que há outras dimensões que, assim, podem, de certo modo, se tornar "invisíveis". E, a julgar pela sua dimensão territorial pouco esclarecida, iniciativas de formular políticas regionais são consideradas inexistentes - não reconhecidas enquanto tais - ou fracassadas.

Como já anunciado antes, o presente trabalho procura mostrar como uma outra dimensão, que já foi chamada de "potencialidades" de formulação ou mesmo implantação de políticas, pode contribuir para sua melhor compreensão ${ }^{13}$.

12 A respeito da avaliação dos instrumentos das políticas regionais, o objetivo de Portugal (2017) "é identificar quais caminhos os atuais instrumentos da Política de Desenvolvimento Regional (PDR) brasileira (Fundos Constitucionais de Financiamento, Fundos de Desenvolvimento Regional e Incentivos Fiscais) estão trilhando e os seus desdobramentos sobre a sociedade".

13 Vide a tese de doutorado de Costa (2016), que aborda tanto criação e recriação da Sudene, não apenas em termos dos seus (magros) resultados, mas também busca sistematizar os condicionantes sociais e políticos de sua trajetória. 


\section{A institucionalização de seletividades e a produção política de não-acontecimentos no Estado capitalista ${ }^{14}$}

Como se viu no item anterior, ao avaliar superficialmente a experiência brasileira de formulação e implantação de políticas de desenvolvimento regional em nível federal é difícil julgá-las, definitivamente, em relação à sua inexistência, inviabilidade ou mesmo fracasso. Sua realidade é complexa demais para ser resumido a um juízo tão simples. Longe de querer dar por terminada a discussão sobre resultados ou mesmo abandonar essa "dimensão de sua natureza", a presente investigação procura mostrar que uma avaliação pelos resultados - "fracassos" - não será suficiente para compreender essas políticas.

Como já anunciado acima, para superar um víeis possível positivista na apreciação de políticas "resultados" precisam ser compreendidos, também, como uma forma de exclusão de outras possibilidades. "Nãoacontecimentos" ${ }^{15}$ são tão "resultados" como os próprios; sua produção ocorre concomitantemente à afirmação de determinados resultados. São expressão de "potencialidades" de uma política, que, geralmente, são apenas mencionadas marginalmente como "vencidas", "eliminadas". A identificação e qualificação dessa dimensão como "significativa” não será 'possível pela mera observação dos fenômenos aparentes, mas exigirá uma compreensão de processo responsáveis pela sua "produção". Neste sentido, defende-se aqui que há outras "dimensões" cujo caráter de serem "significativas" precisa ser mais bem compreendido. Apesar de serem apontadas, de vez em quando, em uma parte das apreciações das políticas, o significado dessas dimensões geralmente é pouco reconhecido.

Ao interpretar fenômenos como "não-acontecimentos" - e não como simples inexistências - atribui-se, a esse, seu "verdadeiro" caráter de resultado de processos sócio-políticos de inclusões/exclusões e não como falta de um objeto do mundo físico-natural, que simplesmente não está presente. Um aprofundamento da discussão sobre a diferença entre ausência e não-acontecimento levantaria, em última instância, questões metodológicas e até epistemológicos (vide RANDOLPH 2015) que não serão abordadas aqui ${ }^{16}$.

14 Os dois itens seguintes retomam, ao ampliar e aperfeiçoar uma reflexão sobre seletividade e governança, um estudo anterior (RANDOLPH 2017).

15 Vide Randolph (2017).

16 Essa não é nenhuma questão "esotérica" porque qualquer esforço de planejamento, projeção e prospecção e, como o presente caso, desenho de políticas enfrenta o desafio 
A compreensão destes processos passa pela identificação dos (complexos) mecanismos que produzem tanto seu não-acontecimento como de processos (geralmente concomitante) que o "naturalizam", ou seja, que tornam "invisíveis" seu caráter de produto social. Algo que, talvez, em analogia ao fetichismo da mercadoria, possa ser denominado um "fetichismo" da decisão.

Tendencialmente, se colocaria, então, o enorme desafio em identificar tanto aqueles agentes sociais, sujeitos das ações, que lutaram, possuindo uma certa potencialidade virtual para tal, a favor de que um fenômeno aconteça, como aqueles que se opuseram e conseguiram impedir que essa virtualidade se tornasse "real" ${ }^{17}$. Ou seja, em relação à temática atual de políticas regionais, ao invés de ficar analisando os elementos de uma proposta que não se reconhece como política regional, é necessário desvendar os mecanismos - as "seletividades", como será argumentado adiante - que impediram seu "acontecimento" e mesmo o reconhecimento de seu caráter sócio-político.

Esse trabalho se tornaria uma tarefa quase impossível se não tivesse certos "lugares" nas sociedades capitalistas que, com relação à formulação e implementação de políticas públicas, são privilegiados e responsáveis tanto para sua execução e seus resultados, como, concomitantemente, para a "produção" sistemática de seus não-acontecimentos. O desafio se desloca, então, para a tarefa de encontrar esses mecanismos (sociais, políticas, econômicos) que são responsáveis, sistematicamente, por esta produção.

No nosso caso, adiantamos, são as dimensões institucional e da ação política que precisam ser consideradas para compreender o "verdadeiro"

de trabalhar com "virtualidades"; falando genericamente, a identificação de "não-acontecimentos" exigirá a investigação dos agentes envolvidos nesta "produção", suas agências, lugares e dinâmicas responsáveis para este (não) resultado - tanto daqueles que contribuíram para a virtualidade do acontecimento (LEFEBVRE, 1999, p.16), como daqueles que acabaram por impedir que essa virtualidade se realizasse. $\mathrm{Ou}$ seja, não-acontecimentos pressupõem a "virtualidade" de acontecimentos. Em outras palavras, a ausência de algum fenômeno social, ao ser produzida deliberadamente, significa um não-acontecimento (RANDOLPH 2015).

17 Em princípios, "não-acontecimentos" fazem parte da própria vida cotidiana porque, na maioria das vezes, qualquer passo ou ação realizada pressupõe (conscientemente ou não) alguma escolha de "inclusão/exclusão": excluem possibilidades que poderiam ter sido realizadas; e mesmo quando algo parece "impossível" o pode ser porque a falta de possibilidades é social e politicamente produzida; sem mencionar aqui aqueles "não-acontecimentos" que resultam das relações sociais de produção numa sociedade, mas podem aparecer como "naturais. 
significado de uma política regional. Apenas assim será possível encontrar algo que o simples "resultado" de uma política não mostra (cumprimento ou não dos objetivos de sua ação instrumental); resultado que é apenas uma expressão aparente, um mero fenômeno que não representa a totalidade de uma política.

À medida em que a problemática do "não-acontecimento" de uma politica regional está situada no contexto da formulação de políticas, ela deve ser situada em relação às relações entre sociedade e Estado ${ }^{18}$. Não obstante de ser necessário contemplar "não-acontecimentos" dentro do espectro dessas relações, acredita-se ser possível se restringir a levar em conta um certo protagonismo do Estado, que seria o "lugar" que concentra certas "condições estruturais" de sua produção"19.

Sem entrar em maiores detalhes, para as seguintes breves observações sobre o Estado, optou-se pela apropriação de ideias de dois autores: Nicos Poulantzas e Claus Offe.

Como sintetizado por Miguel (2014, p. 150), Offe nem recorre a relacionamentos especiais entre os detentores do poder e a burguesia (elite) e não precisa apelar a "estruturas" ou outros mecanismos externos para o Estado atender à racionalidade dos interesses do capital, o que vai lhe assegurar seu financiamento ${ }^{20}$ Há uma dependência estrutural do Estado democrático organizado que impede, objetivamente, a tomada de medidas que afetam os níveis de remuneração aceitáveis pelo capital. Seu desrespeito provocaria retração da atividade econômica e risco para o

18 Na presente discussão as relações se referem a sociedades capitalistas democráticas e respectivos Estados capitalistas; torna-se necessário dedicar-se, minimamente, à investigação do Estado, o que permitirá, também, compreender a sistemática e intencionalidade dessa produção como referência conceitual para a reflexão no atual texto.

19 Em outro lugar (RANDOLPH 2019), ao discutir a formulação de agendas políticas, apoiamos na concepção das três arenas de Offe (1981, p. 128s), que não são hierárquicas, mas circulares. Para ele, o processo de influenciar a formulação de políticas (e conquistar posições hegemônicas) pode "ser melhor compreendido, se o imaginamos composto de três níveis ou três arenas de conflitos, dispostas uma sobre a outra" (OFFE, 1981, p. 128). "Embora o espaço de ação do primeiro nível ('política formal') seja, em grande parte, determinado pela matriz do poder social ('segundo nível'), é ele próprio, capaz de facilitar e promover uma revisão das bases normativas e das interpretações da distribuição do poder social ('terceiro nível')" (OFFE, 1981, p. 131).

20 Com isto Offe (1984, p.144) se distancia de abordagens de outros autores a respeito do Estado capitalista que o entendem ou meramente como instrumento neutro (estruturalistas) ou como unicamente determinado pelos interesses da burguesia (participação direta dos membros da classe dominante no aparelho do Estado (Miliband). 
financiamento do Estado - processos que foram de fácil identificação no Brasil dos últimos anos.

Dessa dependência, Offe deriva aquilo que chama a "seletividade sistêmica" que se origina na "seletividade das instituições" e é imposta "pelas estruturas e processos organizacionais do sistema político", que serve tanto para decantar um interesse global da classe capitalista ${ }^{21}$, quanto para bloquear manifestações anticapitalistas (OFFE 1984, pp. 148-50; MIGUEL 2014, p. 150).

Para Offe, a sistematicidade de diferentes formas de seletividade é uma das características fundamentais do Estado capitalista e, assim, "chave-mestre" para abrir seus "segredos". Em nossa opinião, sua forma e expressão - até, no caso extremo, "ausência" ou não-acontecimento - poderia servir para caracterizar a particularidade de um Estado e sua relação com a sociedade ${ }^{22}$. Ainda mais, o autor argumenta que essa seleção sistemática permite a preservação de uma aparente neutralidade de classe, fundamento para a dominação de uma classe ${ }^{23}$. É assegurada, pelos processos de seletividade, a restrição sistemática de um espaço de virtualidades ou possibilidades - através dos quais a dominação política (classista) é exercida ${ }^{24}$.

21 Seria interessante desvelar as particularidades desses processos de "seletividade" na história das relações entre Estado e sociedade no Brasil - objeto de futura investigação.

22 Offe argumenta que o Estado é classista à medida que privilegia sistematicamente determinados interesses de classes em detrimentos aos de outras. Ou como diz o próprio autor: "O problema estrutural do Estado capitalista é que ele precisa simultaneamente praticar e tornar invisível o seu caráter de classe. As operações de seleção e direcionamento de caráter coordenador e repressor, que constituem conteúdo de seu caráter classista, precisam ser desmentidas por uma terceira categoria de operações seletivas de caráter ocultador: as operações divergentes, isto é, as que seguem direções opostas" (OFFE 1984, p. 163, destaque nosso). A falta dessa "sistematicidade" da seletividade, no caso brasileiro, torna aparente, muitas vezes, seu caráter não apenas classista, mas autoritário, patrimonialista e oligárquico.

23 Se poderia aqui discutir a contribuição do planejamento tecnocrata ou racional para construir e/ou apoiar essa aparência de neutralidade do Estado por meio de seu "cientificismo";

24 "Essa seletividade se constitui por meio de um processo dialético (circular): sua institucionalização em determinados aparelhos estatais é tanto resultado como condição da disputa pelo poder entre forças sociais e políticas. Em outras palavras, as próprias instituições são resultado das disputas entre diferentes interesses políticos e sua distribuição manifesta aquela seletividade sistemática. ... (Determinam) quais as "demandas" submetidas ao atendimento que serão acatadas e apoiadas e quais aquelas que nem entram nas agendas políticas - ou seja que tem o destino do "não-acontecimento" (RANDOLPH 2015). 
A corriqueira falta da "sistematicidade" dessa seletividade institucional no caso brasileiro torna aparente, muitas vezes, seu caráter não apenas classista, mas autoritário, patrimonialista, oligárquico e precariamente democrático. Nestas condições os não-acontecimentos não apenas expressam uma seletividade repressiva ${ }^{25}$, mas o Estado, por seus aparelhos repressivos, lança mão de seletividades divergentes - ou seja perde uma coerência racional do seu discurso e sistematicidade da sua atuação quando privilegia, pontual e aleatoriamente, determinados interesses e demandas. Ou seja, pode prejudicar a necessidade de o Estado contar com uma determinada lealdade mesmo dos membros de classes subalternas que obriga governos, quando pressionados, a atender, ao menos parcialmente, a determinadas reinvindicações.

Assim, "instituições definem as regras do jogo político e, enquanto tais, definem quem pode jogar e como pode jogar. Instituições podem determinar quem ganha e quem perde; ... o termo instituição pode ser facilmente substituído por 'poder ou 'detentores de poder social'" (OFFE 2006, p. 9).

Como se pode deduzir da abordagem de Offe de uma forma genérica, um não-acontecimento poderia ser expressão da conjunção de seletividades divergentes, que resultam em uma atuação de aparente incoerência de um governo, mas tem sua "coerência" no fato que é expressão (dialeticamente) "coerente" das dependências estruturais do governo que o limitam (e o Estado através das suas instituições) a lidar, sistematicamente, com as contradições que o atravessam.

Portanto, para propostas tecnicamente competentes e pertinentes de desenvolvimento regional - vide aquelas das políticas acima discutidas - serem realmente aprovadas e implementadas, elas terão que satisfazer os critérios definidos por determinados "filtros" institucionais ${ }^{26}$ estabelecidas no Estado. Ou, à medida que tem, em princípio, um potencial de

25 A regulação (seletividade) exercida pelo Estado tem três formas, expressando-se a sistematicidade por: (a) uma atuação de afirmação; mas também por (b) uma atuação de repressão, à medida que, de maneira quase imperceptível, reprime certas demandas que podem ser tanto de segmentos do capital como oriundas de reivindicações por parte das classes subalternas (trabalhistas, forças anticapitalistas); e, finalmente, por (c) uma atuação divergente, que revela as limitações do Estado capitalista em lidar com os antagonismos de uma sociedade capitalista, mesmo em regimes democráticos.

26 Como mencionado, exigências de remuneração aceitável para compromissos e investimentos por parte do capital podem ser "filtros" numa sociedade capitalista. Ou seja, políticas podem ser "coerentemente" implementadas apenas se respeitarem essas exigências, se não ameaçarem os níveis aceitáveis de remuneração. Ou, então, a 
dar origem a novas institucionalidades, realizar este potencial e alterar seletividades existentes (institucionalizadas) através de um excepcional apoio político e administrativo. Tanto a trajetória da Sudene (e da política regional para o Nordeste) como a trajetória recente das PNDRs são dois exemplos diferentes de "enfrentamento" de diferentes formas de seletividades ${ }^{27}$.

Na hora da sua formulação e implementação, a política regional para o Nordeste e a Sudene estavam conceituadas para ajudar superar velhas "estruturas" e apoiar novas hegemonias (burguesia industrial). Exigia, para tanto, a institucionalização por meio de um órgão que pudesse estabelecer "seletividades" neste sentido (apenas atender determinadas demandas). Obteve apoio, incialmente, para este projeto porque a questão nordestina foi interpretada (em certos discursos) como questão nacional.

Já no caso da PNDR, ela se iniciou por uma formulação em 2003 que apenas foi institucionalizada em 2007 - até então não superou os obstáculos que diferentes formas de seletividades criaram. Sua formalização precisava da força política por ocasião da reeleição do então presidente, mas mesmo assim só a foi por decreto presidencial e sua execução foi atribuída a um ministério sem uma força político-administrativa muito grande.

No entanto, o caso da Sudene mostra claramente como a criação de "filtros seletivos", num primeiro momento, não foi nenhuma garantia que, durante a execução da política, estes não podem ser alterados de uma forma a colocar em risco ou quase inviabilizar a realização do projeto que lhe deu origem ${ }^{28}$. Ou seja, durante um certo período, podem ter

"potencialidade" (virtualidade) de implantação das políticas aumenta caso manifestações anticapitalistas consigam levar os investidores a reverem suas taxas de lucro.

27 Não será possível explorar aqui este aspecto que, na verdade, iria aprofundar a questão da "existência" de potencialidades. Em relação tanto à Sudene como às primeiras duas formulações de políticas regionais em nível nacional no novo século, há fortes indícios (em formas de grupos de trabalho, documentos programáticos, relatórios, livros), da preparação e mesmo da formulação e sua institucionalização das políticas, que já foram amplamente discutidas na literatura, mas que poderiam ser reinterpretados na perspectiva do atual trabalho. Vide Furtado (1962) e, também, Bernardes e Lima (2010).

28 Há uma literatura extensa sobre este projeto; mas, parece-nos que seria necessário retomar essa discussão a partir da recuperação do texto fundamental de Celso Furtado de 1962 que, infelizmente, ainda não foi possível, no atual texto, incorporar aqui essa discussão. 
existido condições (uma "potencialidade") para formulação, aprovação e, até, implementação das políticas de desenvolvimento regional. Mas, as forças de sua sustentação inicial não foram capazes de manter seu projeto na (primeira) agenda das prioridades ou podem até ser expressão de uma seletividade divergente, que apenas satisfaz interesses muito particulares e de limitado apoio político.

Outro exemplo interessante seria a mobilização em torno da formulação da segunda PNDR, que desembocou até na organização de uma Conferência Nacional de Desenvolvimento Regional e na redação de um projeto de lei com amplo envolvimento de órgãos governamentais em nível federal e estadual, de segmentos profissionais e de comunidades de diferentes estados, um processo de indicação para representação e articulação de agendas etc ${ }^{29}$.

Neste sentido, defende-se aqui, que, em ambos os casos, podem ser encontrados argumentos que apontam para certas possibilidades (probabilidade) de sua realização, seu "acontecimento" - o que aliás se verificou parcialmente ${ }^{30}$. Conforme já discutido antes, nestes casos valeria a pena realizar investigações com maior detalhe e profundidade para além das mencionadas razões (sociedade arcaica e conservadora; falta de apoio político etc.) a fim de identificar e caracterizar aquele processo da produção sócio-político do seu "não-acontecimento".

Em relação à proposta de 2019 de uma política de desenvolvimento regional em nível federal, há de se ter cuidado em tirar conclusões por causa das circunstâncias da publicação do referido Decreto da Presidência, logo após a instauração de um governo cuja plataforma eleitoral não contemplava nem a questão do desenvolvimento regional. A rápida aprovação da proposta poderia, neste caso, ser expressão de uma forma de seletividade divergente.

Apesar de não ser possível entrar em maiores detalhes a respeito das mencionadas políticas regionais ${ }^{31}$, esperamos ter mostrado que as

29 Uma ideia da discussão na fase da articulação da proposta para a PNDR II pode ser encontrada em Randolph e Tavares (2018).

30 E, como acabamos de afirmar, sua possibilidade/potencialidade se manifesta concretamente em propostas, ações ou mesmo na sua (parcial) institucionalização; ou seja, as tentativas não foram "sufocadas" sem ter possibilidade de "aparecer" por uma seletividade repressiva; como discute Offe, muitas potencialidades (prorrogativas, demandas, reivindicações etc.), tem esse destino.

31 Há investigações e análises a seu respeito que não usam a referência conceitual aqui proposta, mas que podem fornecer elementos importantes para um detalhamento das apreciações aqui só provisoriamente detalhada. 
instituições do Estado representam uma "dimensão significativa" para compreender as políticas regionais na sua complexidade.

\section{Estruturas e processos, governança e contradições sócio-políticas}

A institucionalização de seletividades representa o lado estrutural do Estado e cria disponibilidades, mas também certas amarras para um governo. Como dito antes, a atuação de um governo depende, em certa medida, das formas institucionais que encontra, mantêm e/ou altera quando assume o poder e reproduz ou adapta ao seu projeto durante o período da sua gestão ${ }^{32}$.

Para um entendimento melhor da complexidade do "encontro" entre estruturas do Estado e contradições na sociedade e das suas consequências para as politicas se recorre aqui a Poulantzas. Como diz Miguel (2014, p. 154), apesar das trajetórias e bagagens intelectuais diversas de Poulantzas e Offe, as contribuições do último podem ser agregadas à teorização do Poulantzas "pós-estruturalista" sobre a relação entre Estado e luta de classes. As instituições do Estado, para Poulantzas, "não podem ser entendidas como mero instrumento a serviço da classe dominante, nem como um espaço neutro de resolução dos conflitos, mas como a resultante da correlação de forças de determinada formação social em determinado momento de sua história" (MIGUEL 2014, p 154-155)33.

Reconhece-se, especialmente, a proximidade entre as duas perspectivas, de Poulantzas e Offe, por ocasião da ênfase do último ao poder, porque qualquer instituição envolve, de alguma forma, poder social ${ }^{34}$. Para ele, instituições não podem ser analisadas e compreendidas sem a

32 Isto é um processo que é capaz de alterar as agendas dos governos à medida em que as forças políticas e sociais da sociedade se alteram - vide para isto a concepção de Offe das três arenas.

33 Complementarmente ao acima apresentado, Poulantzas aponta para contradições e lutas de classe - o que não permite que o Estado seja considerado uma entidade intrínseca, mas uma relação, ou "condensação material de uma relação de forças entre classes e frações de classe", com instituições próprias, no seio do Estado. "As contradições de classe constituem o Estado, presentes na sua ossatura material, e fabricam assim sua organização" (POULANTZAS, 1981, p. 197). Essa abordagem "materialista" do Estado se aproxima bastante da de Claus Offe.

34 Para Offe (2006, p. 20 ), o poder social se manifesta em um modo de ação que tem o efeito de definir parâmetros para a ação de outros atores sociais, seja em maneiras desfavoráveis ou favoráveis, como visto por aqueles outros. Em ambos os casos, o exercício do poder é conflituoso, controverso e contestado. 
observação do poder social, que tem uma relação complexa com as próprias instituições e cuja dinâmica, por sua vez, é constituinte para aquela do Estado.

Esse formato estrutural/institucional do Estado "moldura", por assim dizer, as ações do governo. "Governar" significa realizar uma série de ações (que estão inscritos nesse quadro institucional), mas precisam responder (em princípio, conforme formas seletivas estabelecidas) a necessidades e demandas varáveis do próprio governo e da sociedade. Como observado acima, há uma "dialética" entre esses aspectos estruturais e dinâmicas: à medida que as estruturas orientam (restringem) o universo das possibilidades de governar, as ações governamentais são capazes de reproduzir ou alterar essas estruturas 35 .

É dentro deste contexto que existem abordagens do conceito de "governança" que se tomam importantes para a atual investigação. Quando observa que as capacidades "governativas" são determinadas por forças e poderes que operam para além das limitações do Estado, Jessop (2004/2014), encaminha essa discussão sobre as seletividades para o termo de governança ${ }^{36}$ - Suas realizações - gestão ou governo que ultrapassa as limitações expressas nas instituições do Estado - interferem no mecanismo de seletividades estruturais/sistêmicas que determinam, como já foi discutido anteriormente, o acesso e suas formas das diferentes classes ou segmentos sociais a Estado e governo.

Vale reter a identificação do autor de uma "seletividade estratégica" que obriga analistas olhar

para além do Estado para examinar a sua incorporação dentro de um sistema político mais amplo, sua relação com outras ordens institucionais e sistemas funcionais, e ao mundo da vida (ou da sociedade civil). Por sua vez, a tentativa de exercício do poder estatal (ou, melhor, os poderes do

35 Eis a expressão simplificada de uma reflexão de Jessop (2004/2014), que vê o Estado embutido em contextos espaço-temporais específicos, onde as instituições produzem consequências específicas e diferenciais (seletividades específicas). Semelhante à discussão antes travada, vê que, conforme a capacidade de diferentes forças políticas e interesses particulares e estratégicas que se expressam através do Estado, têm acesso a ou controle sobre determinadas capacidades dele e de suas instituições.

36 Para Jessop (2004/2014), "em termos gerais, a governança se refere aos mecanismos e estratégias de coordenação adotadas em face da interdependência recíproca complexa entre os atores operacionalmente autónomos, organizações e sistemas funcionais. Assim, governança ocorre em todos os campos sociais e seus estudiosos examinaram uma ampla gama de tais mecanismos e estratégias, incluindo mercados, clãs, redes, alianças, parcerias, cartéis, associações e Estados". 
Estado, no plural) irá refletir algum equilíbrio existente de forças como este é institucionalmente mediada através do aparelho do Estado com a sua seletividade estratégica estruturalmente inscrita (Jessop 2004/2014, tradução nossa).

Essa compreensão torna-se crucial para o debate anterior na medida em que desloca a discussão institucional das seletividades (e de não-acontecimentos) para outras esferas da vida social (organizações fora da esfera estatal) e dos sistemas econômicos (setor privado, mercado etc.). A governança como ação política (e não apensa como conceito) permitiria e mesmo exigiria pensar e compreender as seletividades fora do contexto limitado do Estado, porque "institucionaliza" determinadas formas de responsabilidades da sociedade civil 37 .

Essa "exigência" vai ao encontro com as perspectivas ampliadas sobre o Estado dos autores acima referidos. Abordagens puramente centradas no Estado em termos de gestão ou governo seriam inconsistentes dentro dessa perspectiva "gramsciana/ poulantziana/offeana" - aqui adotada porque pressuporiam que o Estado pode ser examinado isoladamente e tratado como uma variável independente. Foi discutido que tanto Offe (1984, 2006), Poulantzas (1981) e Jessop (2004/2014) propõem abordagens que não pretendem cometer esse equívoco ${ }^{38}$.

Essa discussão da governança precisa ser realizada dentro da perspectiva que estrutura institucional e dinâmica gerencial constituem uma dialética de consolidação e modificação do Estado. Como se viu antes, além da formulação e implementação de políticas governamentais, a própria execução passa por determinados "filtros seletivos", onde se expressa a institucionalidade do Estado, mas que é suscetível a ser modificada por forças políticas envolvidas na sua execução. Se determinam quais as ações os governos podem ou devem tomar, determinam, também, quais não "cabem" no âmbito de determinada política. Assim, a própria dinâmica entre estrutura e processo pode se tornar um círculo vicioso - reproduzir ou reforçar problemas - ou virtuoso - romper gradualmente com o que se reforça.

37 Obviamente, o próprio processo das seletividades leva em conta que havia sempre um "fluxo" de reivindicações , demandas etc. para o governo/Estado, que foram submetidos aos processo de seletividade. E também sempre teve formas de influenciar essas seletividades por mecanismos fora dos governos; talvez a corrupção seja o exemplo mais óbvio; mas havia formas de influenciação legítimas por lobbys etc.

38 Uma apresentação mais detalhada das abordagens destes autores, especialmente Offe e Jessop, mostraria seus posicionamentos em relação à circulação do poder, à institucionalização de seletividades e à articulação entre sociedade política e sociedade civil. 
Foi argumentado, em relação à estrutura do Estado, Offe (2006, p. $10 \mathrm{~s})$, que sua criação precisa ser compreendida como resultado de uma luta entre poderes sociais que, reclama, ao menos rudimentarmente, a reinvindicação de validade, na medida em que não é intencional, instrumental ou orientado para determinados objetivos e possui "ideias de animação", ou alguma teoria implícita que fornece certas razões para seu suporte ou defesa ${ }^{39}$. Ou seja, a formação das instituições é sempre um processo dinâmico dentro do qual a atuação do próprio governo tem sua própria influência.

A nosso ver, entre as diferentes perspectivas ${ }^{40}$ discutidas na literatura, apenas uma, ainda em desenvolvimento, se refere a uma perspectiva de governança, que possibilitaria compreender essa dialética entre estrutura e processo da gestão no sentido que acabamos de anunciar: está voltada para questões de descentralização, diversificação da política (politics and policy) e de regulação. Pode ser interpretada, assim, como um conceito que expande o conceito de governança e procura compreender as relações dinâmicas entre organização, regulação, envolvimento e o papel fundamental de conflitos e contradições sociais.

Permitiria, assim, colocar a discussão sobre a seletividade e produção de não-acontecimento num âmbito mais amplo - como já mostrou o modelo das arenas de Offe - do atravessamento entre sociedade política e sociedade civil; ou mesmo do conceito ampliado de Gramsci (1999).

Uma perspectiva da governança de fundo gramsciana poderia abrir um novo horizonte para a discussão da execução de políticas. Poderia permitir uma perspectiva mais complexa e aprofundada a respeito da questão acima introduzida dos "resultados" da execução de políticas e, assim, avançar para além de uma mera avaliação em falhas, fracassos, inexistências etc.

39 Em particular, instituições aumentam a eficiência de transações na medida em que ajudam a economizar custos na procura, negociação e execução de interações em mercados ou não-mercados. Permitem uma auto-coordenação sem atritos ao oferecerem oportunidades e incentivos. Fornecem continuidade na medida em que a inovação fica mais cara. Finalmente, só em caso de mudanças acidentais e repentinas de condições no mundo externo (crise), perda de plausibilidade moral (conflito) etc., colapso ou falhas institucionais podem acontecer, conforme Offe (2006, p. 14 s).

40 Na sua sistematização das ramificações do debate sobre governança Levi-Faur (2011/2012), identificou quatro vertentes: (i) uma neoliberal ; (ii) uma por este autor chamada "degoverncing"; (iii) uma governança centrada na resiliência do Estado; e (iv) uma que se encontrava ainda em fase de gestação que explora as relações entre "governo" e "governança" de um ponto de vista regulatório que pavimenta um caminho para algo que pode ser chamado de capitalismo regulado ou regulatório (RANDOLPH 2017). 
Em articulação com as seletividades institucionais, poderia se constituir como uma verdadeira "dimensão" que mereceria maior atenção na discussão das políticas regionais que fornecem o horizonte político-histórico do atual estudo. Pois, a produção de não-acontecimentos não é limitada ao Estado, mas ocorre também nas estruturas políticas e sociais (classes, segmentos, grupos etc.) da sociedade ${ }^{41}$.

Uma interpretação das experiências de execução (e dos resultados) da política regional do nordeste - enquanto política nacional - e da primeira PNDR poderia, certamente, exemplificar melhor e dar maior concretudo a essa discussão da governança. Por limitações de espço e tempo, isto vai ter que ser postergado para um outro momento.

O que se pode dizer é, como mostra a referência deste estudo às políticas de desenvolvimento regional, a produção de "não-acontecimentos" remete a questões da exclusão de classes subalternos na sua formulação e da manutenção de velhas hegemonias, cuja "superação" - um dos objetivos da Sudene - (exclusão e reprodução de hegemonia) foi ao menos não como um dos objetivos cujo "acontecimento" não pode ser.

Para identificar possibilidades da superação de "exclusão" e "velha hegemonia" ter "acontecido", seria necessário reconhecer respectivas potencialidades na sociedade brasileira nos diferentes períodos históri$\cos ^{42}$. Seria, provavelmente, fortalecer a "presença" de interesses de classes subalternas nos fóruns ou arenas de circulação do poder (contra as acima mencionadas "forças arcaicas e conservadoras").

\section{Incapacidade ou "não-acontecimento"? À guisa de uma conclusão}

O que se queria salientar aqui ao final do presente estudo é que as duas experiências mostram dois formatos bem diferentes, refletindo as possibilidades dos espaços e tempos históricos de sua formulação e execução. Mesmo ao procurar ter o maior cuidado para não desqualificar os esforços envolvidos e, também, resultados obtidos, parece-nos pertinente levantar aquela interrogação que consta no título deste capítulo.

41 Vide, mais uma vez, a concepção das arenas de Offe como uma aproximação a esta problemática;

42 Parece tentador, elaborar uma "história virtual" a respeito de oportunidades perdidas para a sociedade brasileira; e acompanhar, no tempo, os momentos e características destes não-acontecimentos"; não muda a história, mas pode permitir um melhor aprendizado do passado para projetar o futuro. 
Uma certa descrença em relação à utilidade, para o debate, do julgamento de "fracasso" (ou mesmo "sucesso") das políticas nacionais de desenvolvimento regional no Brasil a partir do resultado de sua execução ou institucionalização perde, neste sentido, uma parte de sua relevância. Não obstante parecem mais interessantes aquelas apreciações que não julgaram as políticas dentro dos parâmetros dos resultados de sua formulação e/ou execução. Apresentam argumentos a respeito da competência das propostas e da sua competência ao propor medidas e instrumentos com alguma (discutida) potencialidade de contribuir para que o objetivo central das políticas - a redução das desigualdades inter-regionais no Brasil - pudesse ser cumprido.

Neste sentido, a pergunta em relação à responsabilidade de uma "incompetência" (técnica/instrumental) na formulação e/ou execução das políticas pela sua falha pode ser negada - desconsiderando eventuais menores problemas. Seria interessante observar mais de perto esta questão em relação à política para o desenvolvimento do Nordeste e as duas versões da PNDR, o que vai ter que ser deixado para ouro momento.

Uma identificação das características e das eventuais causas ou razões das políticas não lograrem reduzir as desigualdades regionais - parece este "fato" ser mais ou menos consensual - se tornou necessário, então, procurar outras "variáveis" ou, ao seguir o conselho de Celso Furtado, "dimensões" que permitiriam perceber a complexidade dos fenômenos.

Pressupondo tratar no universo do nosso estudo de fenômenos com um certo grau de complexidade, procuramos dimensões que pudessem ter uma influência no "fracasso/sucesso" de uma política de desenvolvimento regional. E, ao invés, de atribuir às políticas um status de simples "não-existência", procuramos compreender essa "inexistência" como produto ou "resultado" de processos sociais e políticos.

Se não se quer simplesmente excluir sua existência, pode-se admitir que processos sociais e políticos que foram mobilizados para sua produção não conseguiram assegurar seu "acontecimento". Um potencial "acontecimento" não se realizou e deu lugar a um "não-acontecimento" - ou seja há, nesta produção social e política, uma relação dialética entre acontecimento/não-acontecimento, porque sem um potencial/virtual acontecimento, não haveria um não-acontecimento ${ }^{43}$.

43 Usamos, em outro lugar, o exemplo da "inexistência" do sol durante a noite em um determinado lugar. Não se trata aqui de um "não-acontecimento" por ser resultado de um processo natural que excluí qualquer possibilidade do sol aparecer na noite. 
Em outras palavras, é o processo de produção do acontecimento/não -acontecimento que vai poder confirmar se um "não-acontecimento" está acontecendo. Foi mostrado, nos itens anteriores, qual a dinâmica e os mecanismos que estão envolvidos na produção destes acontecimentos/ não-acontecimentos.

Para redimir a dúvida, expressa no título do texto a respeito da "existência" de uma política nacional de desenvolvimento regional no Brasil, seria necessário seguir, particularmente, os processos de seletividade nas suas formas mais gerais. Obviamente, a breve apresentação acima dos dois momentos da formulação e/ou execução de políticas que se propuseram contribuir ao desenvolvimento regional não permite chegar a uma conclusão a respeito de seu status. Em nível de certa plausibilidade e sem emitir nenhum juízo definitivo poderia se identificar elementos que descartam tanto sua avaliação como simples fracasso, bem como propostas incompetentes, mas, talvez, por causa de uma certa potencialidade, como "não-acontecimentos".

Enfim, ao vincular a atual discussão das políticas a questões do Estado - como muitos outros autores também fazem; menos, talvez os economistas que estão muito presentes no campo do desenvolvimento regional - entram em cena outras temáticas que poderiam ser importantes para pensar no "futuro" em políticas de desenvolvimento regional.

Vale lembrar de uma afirmação de Celso Furtado que já foi mencionada antes. Fala o autor da necessidade de uma reconstrução da temática:

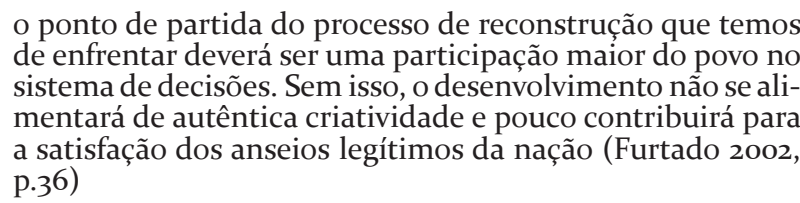

Acredita-se que Furtado, como já o fizeram outros, toca aqui num ponto de maior importância. E, implicitamente, temos a esperança que a discussão apresentada neste texto pode dar alguma, ainda que limitada, contribuição para esta reconstrução - que ainda há de ser feita, mesmo que fosse apenas para compreender a profundidade do desafio que Celso Furtado nos faz.

Pois, como mencionado acima, a análise de um fenômeno como "não-acontecimento" vai dirigir a atenção, no caso de políticas públicas, aos mecanismos de seletividade que são os principais responsáveis por sua produção. Remete a questões de poder e da inclusão/exclusão por 
determinadas estruturas, instituições e dinâmicas: classes, segmentos, grupos sociais e especialmente aqueles que, estruturalmente, não são envolvidos e contemplados pelas políticas. E vai mostrar limites que essas estruturas e dinâmicas colocam para transformar em futuras propostas um "acontecimento" que contemple aqueles que hoje são sistematicamente excluídos.

Em seu debate sobre um aprofundamento da democracia, Miguel (2014) trava essa mesma discussão em relação aos limites que o atual quadro de instituições impõe. A abordagem dos "não-acontecimentos" pode, em analogia ao caso discutido pelo autor,

evidenciar os limites tanto da mera incorporação de integrantes de grupos subalternos aos espaços decisórios já constituídos (a "política de presença" propugnada pelo movimento feminista a partir dos anos 1990) quanto da abertura de arenas marginais na estrutura do Estado, que seriam mais permeáveis às demandas dos grupos dominados (os novos espaços participativos, como conferências, conselhos de políticas públicas ou orçamentos abertos à manifestação popular, para citar exemplos em voga na ciência social brasileira)" (MIGUEL 2014, p. 158).

Sem poder aprofundar aqui, o debate trazido por Miguel dá uma impressão de como os mecanismos de seletividade e as estruturas políticas são capazes de neutralizar a eventual presença de membros de grupos subalternos ${ }^{44}$. O conhecimento da força e da resiliência dos mecanismos de reprodução da dominação social mostra a necessidade de se resistir a mecanismos "imunes" de cooptação através de recompensas simbólicas e materiais para aqueles que aceitam "jogar o jogo" da política normalizada (MIGUEL 2014, p. 160).

\section{Referências}

ALMEIDA, J.E., ARAÚJO, J.B. Um modelo exaurido: a experiência da Sudene. Teor. e Evid. Econ. Passo Fundo v. 12 n. 23, 2004, p. 97-128

BERNARDES, D., LIMA, M.C. Celso Furtado e a pré-revolução brasileira. maio 2010 https://www.acessa.com/gramsci/?page=visualizar\&id=1235; acesso em 15.04.2020

44 Há uma literatura sobre este assunto que traz diferentes abordagens de resistência, insurgência até de subversão como formas de reação para escapar deste risco, vide p.ex. Randolph 2014 . 
BRANDÃO, C. Desenvolvimento nacional, políticas regionais e o poder de decisão segundo Celso Furtado. Cadernos do Desenvolvimento, vol. 5 (7), 2010, p. 101- 115

BRANDÃO, C. Avançamos na PNDR II, mas falta transformá-la em uma estratégia de Estado. Revista Política e Planejamento Regional (RPPR), Rio de Janeiro, v. 1, n. 2, julho/dezembro 2014, p. 339-344

BRASIL PRESIDÊNCIA DA REPÚBLICA, Decreto № 6.047 , de 22.02.2005, Brasília 2007

BRASIL PRESIDÊNCIA DA REPÚBLICA, Decreto № 9.810 de 30.05.2019, Brasília, 2019

CARVALHO, O. Perspectivas do desenvolvimento regional no Brasil. Revista Política e Planejamento Regional (RPPR), Rio de Janeiro, v. 1, n. 2, 2014, p. 295 a 310

COELHO, V.L.P. A política regional do governo Lula (2003-2010) Revista Política e Planejamento Regional (RPPR), Rio de Janeiro, v. 2, n. 2, 2015, p. 265-286

COSTA, M.R. O Estado e a Sudene: Trajetória do planejamento regional no Brasil. Campinas, SP: UNICAMP, 2016, (tese de doutorado)

FURTADO, C. A pré-revolução brasileira. Rio de Janeiro: Editora Fundo da Cultura, 1962

FURTADO, C. Em busca de novo modelo: reflexões sobre a crise contemporânea. São Paulo: Paz e Terra, 2002.

FURTADO, C. O mito do desenvolvimento econômico. Rio de Janeiro: Paz e Terra, 1974

GRAMSCI, A. Cadernos do cárcere. Rio de Janeiro: Civilização Brasileira 1999

GTDN. Uma política de desenvolvimento econômico para o Nordeste. 2.ed. Recife: Sudene, 1967.

GUIMARÃES NETO, L. Desafios para uma Política Nacional de Desenvolvimento Regional no Brasil. Entrevista especial com Leonardo Guimarães Neto. Entrevistadores: J. Natal e H. Siqueira (realizada em março de 2011), R. Pol. Públ., São Luís, v.16, n.1, jan./jun. 2012, p. 203-207 
GUMIERO, R.G. A trajetória das politicas de desenvolvimento regional do Nordeste: balanço entre a Operação Nordeste e a PNDR. Revista Politica e Planejamento Regional (RPPR), Rio de Janeiro, v. 4, n. 2, 2017, p. 189 a 210

HORSTH, T.A., ALMEIDA, F.M., MENDES, W.A. Efeitos das recriações da SUDAM e da Sudene no desenvolvimento socioeconômico municipal. Trabalho publica nos anais do IV Encontro Brasileiro de Administarção Pública, João Pessoa, maio 2017

JESSOP, B. Multi-level governance and multi-level meta-governance. Changes in the EU as Integral Moments in the Transformation and Reorientation of Contemporary Statehood, in I. Bache and M. Flinders, eds, Multi-Level Governance, Oxford: OUP, 49-74, 2004. - on-line version is the pre-copyedited, preprint version 2014: http://bobjessop. org/2014/o1/10/multilevel-governance-and-multilevel-metagovernance/

LEFEBVRE, H. A revolução urbana. Belo Horizonte: Editora UFMG, 1999

LEVI-FAUR, D. From big government to big governance? Jerusalem Papers in Regulation \& Governance, Working Paper No. 35, July $2011 / 12$

MACEDO, F.C., PORTO, L. Existe uma Política Nacional de desenvolvimento Regional no Brasil? G\&DR - Taubaté, SP, v. 14, n. 2, 2018, p. 605-631 MIGUEL, L. F. Mecanismos de exclusão política e os limites da democracia liberal. Uma conversa com Poulantzas, Offe e Bourdieu. Novos Estudos CEBRAP, no 98, março 2014, p. 145-161

OFFE, C. Algumas contradições do Estado social moderno. In: Offe, C. Trabalho e sociedade. Perspectivas. Rio de Janeiro: Tempo Brasileiro 1981, p. 113-131

OFFE, C. Dominação de classe e sistema político. In: Offe, C., Problemas estruturais do Estado capitalista. Rio de Janeiro: Tempo Brasileiro, 1984, p. 140-179

OFFE, C. Governance: An "Empty Signifier"? Constellations 16, 2009, p. $55^{-}-562$ 
OFFE, C. Political institutions and social power: conceptual explorations. In: I. Shapiro; S. Skowronek; D. Galvin (Eds). Retinking political institutions. The art of the state. New York, London: New York Ubiversity Press 2006, p. 9-31

PESSOA, S.R.N., MILANI, A.M.R. A invenção criadora da GTDN e o desenvolvimento econômico sob a ótica de Schumpeter: o empresário inovador como elemento de convergência. Revista Economia Política do Desenvolvimento, v.6, n. 16, 2013, p.123-144

PITANGA, P.A. Os desafios a uma Política Nacional de Desenvolvimento Regional no Brasil. INTERAÇÕES, Campo Grande, v. 15, n. 1, 2014, p. 175-192

PORTUGAL, R. O que dizem as avaliações da política de desenvolvimento regional np Brasil? Rev. Econ. NE, Fortaleza, v. 48, n. 3, 2017, p. 157-170,

POULANTZAS, N. O Estado, o poder, o socialismo. Rio de Janeiro: Graal 1981 (publicado originalmente em francês em 1978).

RANDOLPH, R. Subversão e planejamento como "práxis", uma reflexão sobre uma aparente impossibilidade. In: LIMONAD, E.; CASTRO, R. E. (Orgs.) Um novo planejamento para um novo Brasil? Rio de Janeiro: LetraCapital 2014, p. 40-57

RANDOLPH, R. Arenas de formulação de políticas regionais: uma proposição metodológica. Revista Brasileira de Desenvolvimento Regional, v. 3, 2015, p. 5-26.

RANDOLPH, R. Política, planejamento e governança do desenvolvimento regional - quo vadis? Redes - Santa Cruz do Sul: Universidade de Santa Cruz do Sul, v. 22, n. 1, 2017. p. 218-239

RANDOLPH, R. Quo vadis, planejamento e desenvolvimento regional? Apresentação na Mesa Redonda VI: Perspectivas e Avaliação da Área de PUR no Brasil no IV SEDRES. Palmas-TO: UFT, 2018

RANDOLPH, R. Fóruns Políticos, Exercício do Poder e Agendas Regionais: contextos para a formulação de políticas regionais de desenvolvimento no Brasil In: RANDOLPH, R. BARBOSA, G.S., ANTUNES, L. PEIXOTO, D.F. (Orgs) Consórcios Intermunicipais e Comitês de Bacia Hidrográfica - Suas potencialidades e limitações para formular agendas de 
desenvolvimento regional no Brasil, Rio de Janeiro: Hexis Ed. 2019, p. $31-47$

RANDOLPH, R., TAVARES, H.M. (Orgs.) Política e planejamento regional - uma coletânea. Brasília-DF: Gráfica Movimento, 2013

SILVA, L.P. Análise da trajetória institucional de implementação da Política Nacional de Desenvolvimento Regional no Brasil. Rev. Serv. Público, Brasília vol. 67 (3) 2016, p. 351-376

SILVA, S.A. A PNDR e o planeamento regional brasileiro no início do século XXI. Texto para discussão no. 2150, IPEA - Brasília: Ipea 2015 